\title{
Patterns of antibiotic use and risk of hospital admission because of Clostridium difficile infection
}

\author{
Sandra Dial MD MSc, Abbas Kezouh PhD, Andre Dascal MD, Alan Barkun MD MSc, Samy Suissa PhD
}

$\infty \quad$ See related commentary by Kuijper and van Dissel, page 747

\section{ABSTRACT}

Background: Previous observations have indicated that infection with Clostridium difficile occurs almost exclusively after exposure to antibiotics, but more recent observations have suggested that prior antibiotic exposure may be less frequent among cases of communityacquired disease.

Methods: We used 2 linked health databases to perform a matched, nested case-control study of elderly patients admitted to hospital with community-acquired $C$. difficile infection. For each of 836 cases among people 65 years of age or older, we selected 10 controls. We determined the proportion of cases that occurred without prior antibiotic exposure and estimated the risk related to exposure to different antibiotics and the duration of increased risk.

Results: Of the 836 cases, $442(52.9 \%)$ had no exposure to antibiotics in the 45-day period before the index date, and $382(45.7 \%)$ had no exposure in the 90-day period before the index date. Antibiotic exposure was associated with a rate ratio (RR) of $10.6(95 \%$ confidence interval $[\mathrm{Cl}]$ 8.9-12.8). Clindamycin (RR 31.8, $95 \% \mathrm{Cl} 17.6-57.6$ ), cephalosporins (RR 14.9, 95\% Cl 10.9-20.3) and gatifloxacin (RR 16.7, 95\% Cl 8.3-33.6) were associated with the highest risk. The RR for $C$. difficile infection associated with antibiotic exposure declined from $15.4(95 \% \mathrm{Cl}$ $12.2-19.3)$ by about 20 days after exposure to $3.2(95 \% \mathrm{Cl}$ 2.0-5.0) after 45 days. Use of a proton pump inhibitor was associated with increased risk (RR 1.6, 95\% Cl 1.3-2.0), as were concurrent diagnoses of inflammatory bowel disease (RR 4.1, 95\% Cl 2.6-6.6), irritable bowel syndrome (RR 3.4, 95\% Cl 2.3-5.0) and renal failure (RR 1.7, 95\% Cl 1.2-2.2).

Interpretation: Community-acquired C. difficile infection occurred in a substantial proportion of individuals with no recent exposure to antibiotics. Among patients who had been exposed to antibiotics, the risk declined markedly by 45 days after discontinuation of use.

Une version française de ce résumé est disponible à l'adresse www.cmaj.ca/cgi/content/full/179/8/767/DC1

CMAJ 2008;179(8):767-72

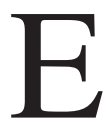
arly observations that infection with Clostridium difficile occurred almost exclusively after antibiotic exposure $^{1}$ gave rise to the concept that antibiotic-induced alteration of the intestinal flora was a prerequisite for its occurrence. ${ }^{2}$ Consequently, reports that a significant proportion of patients are infected with $C$. difficile in the community without antecedent antibiotic use $\mathrm{e}^{3-5}$ have been controversial; these reports, if confirmed, could change our understanding of $C$. difficile as a human pathogen. ${ }^{6}$

Bartlett $^{7}$ has suggested that the role of the hospital was not clearly recognized in early epidemiologic studies of $C$. difficile. The hospital environment has many characteristics that likely contribute in important ways to the occurrence and transmission of infectious disease, in particular, clustering of susceptible hosts, environmental contamination, physical proximity of patients and multiple person-to-person contacts. In addition, antibiotic use is common in hospitals, ${ }^{8}$ and $C$. difficile is considered by many as a primarily nosocomial disease. This perspective may have contributed to observations that $C$. difficile infection was almost always preceded by antibiotic exposure. Given the potential for an association between hospital admission and antibiotic exposure, studying $C$. difficile in the community, where the prevalence of antibiotic use is much less common, may be a way to decrease the confounding of these closely correlated exposures. Other biases have probably contributed to the almost $100 \%$ prevalence of antibiotic exposure in many reports of $C$. difficile, including ascertainment bias, given that diarrhea is a common side effect of antibiotics; ${ }^{9}$ detection bias, because of guidelines recommending that $C$. difficile testing be limited to patients who have had a recent hospital stay or a history of antibiotic exposure, ${ }^{10}$ and information bias, in that, among toxin-positive patients with diarrhea, the diarrhea is more likely to be attributed to $C$. difficile when there has been recent antibiotic exposure but more likely to be attributed to other causes in the absence of such a history. ${ }^{11}$ Some studies have included prior antibiotic exposure as part of the case definition, ${ }^{12-15}$ which would also ensure $100 \%$ antibiotic exposure in the cases.

From the Department of Medicine (Dial, Dascal, Suissa), the Division of Infectious Diseases (Dascal) and the Centre for Clinical Epidemiology (Kezouh, Suissa), Sir Mortimer B. Davis-Jewish General Hospital, McGill University, Montréal, Que.; the Montreal Chest Institute (Dial) and the Department of Medicine (Barkun), McGill University, Montréal, Que.; and the Divisions of Gastroenterology (Barkun) and Clinical Epidemiology (Barkun), McGill University Health Centre, Montréal, Que. 
The primary objective of our study was to examine patterns of antibiotic exposure among people with $C$. difficile infection in the community. We wished to determine whether our previous findings from the United Kingdom ${ }^{4,5}$ would be reproduced in a different population of high-risk patients, in a different country, with a clinically relevant case definition, that is, hospital admission because of $C$. difficile infection. A secondary objective of the study was to determine the period of risk after antibiotic administration.

\section{Methods}

\section{Study design and data sources}

We performed a matched, nested case-control study among the cohort of all elderly people in the province of Quebec who had been admitted to hospital at least once between 1996 and 2004. We obtained the data for the study from 2 administrative databases: the database of the Régie de l'assurance maladie du Québec and the provincial hospital discharge summary (MED-ECHO) database.

In Quebec, everyone who is 65 years of age or older is eligible for coverage under the provincial health care fund, which is administered by the Régie de l'assurance maladie du Québec. The fund covers the costs of prescription drugs, as well as payments for inpatient and outpatient physician services and other medical services offered in private clinics or hospitals. Data in the records include information on the patient's age and sex, diagnoses, and all filled drug prescriptions and medical procedures for which physician reimbursement occurred. The data for prescription drugs include the drug name, dispensing date, dose, dosage form, treatment duration and quantity of drug dispensed. Drugs dispensed to patients during stays in hospitals or nursing homes are not included in the database. Likewise, medications dispensed in the hospital for patients in outpatient clinics, such as chemotherapy or drugs administered during dialysis, are not included. The hospital discharge summary database (MED-ECHO) provides information about patients who have been admitted to hospital, including discharge diagnosis, comorbid conditions, inpatient procedures, and dates of admission and discharge. Complete coverage for hospital stays is provided for all permanent residents of Quebec, and all dates are captured in the MED-ECHO database. We used unique patient identifiers to link the Régie de l'assurance-maladie du Québec and MED-ECHO databases. These databases have been linked in previous studies, ${ }^{16}$ and they have been shown to be valid for pharmacoepidemiologic research. ${ }^{17}$

This research was approved by the research ethics board of the Montreal Chest Institute. Ethics approval for linking the databases and using the linked data for research purposes was obtained from the Commission d'accès à l'information du Québec.

\section{Selection of cases and controls}

We restricted the study population to patients 65 years of age and older so that we would have complete outpatient prescription records for all cohort members. We included only patients who had had at least 1 hospital stay during the study period (i.e., additional to the hospital stay used to identify patients for inclusion in the study). We defined the follow-up period as starting at the date of discharge from the initial hospital stay.

We identified the cases on the basis of the first hospital admission during follow-up for which $C$. difficile infection (International Classification of Diseases, 9th revision, code 008.45) was listed as the primary diagnosis. The date of admission to hospital for this stay was defined as the index date. If a patient had more than one admission for which $C$. difficile infection was listed as the primary diagnosis, we included only the first of these admissions. We excluded patients in whom C. difficile had been documented as a secondary diagnosis during a previous hospital stay, because we wished to study only incident $C$. difficile infection and wanted to exclude instances of relapse or recurrence. In addition, because we wished to study community-acquired $C$. difficile, we limited our study to patients who had not been admitted to any type of institution in the 90-day period before the index date (i.e., date since hospital discharge for the first stay was more than 90 days before the index date). We also excluded patients who had received a prescription for metronidazole or oral vancomycin therapy in the 90-day period before the index date, as they might have represented cases of C. difficile infection in which the date of onset of infection occurred before the date of hospital admission.

For each case, we randomly selected 10 controls from the study population. Controls were matched to cases in terms of index date and date of first hospital admission in the MEDECHO database to ensure similar duration of follow-up. In addition, as for the cases, we included as controls only people who had not been admitted to hospital and who had not received a prescription for metronidazole or oral vancomycin therapy in the 90 days before the index date. For cases with admission to hospital in the period between 2 years and 90 days before the index date, we matched controls on date of the last hospital admission within 15 days and as much as possible on the number of hospital admissions during the 2-year period before the index date. Both cases and controls had to have a minimum of 1 year prior follow-up recorded in the database.

\section{Assessment of exposure to antibiotics}

Using the Régie de l'assurance maladie du Québec database, we identified all prescriptions for antibiotics and gastric acid suppressant agents, including proton pump inhibitors and histamine $_{2}$-receptor antagonists, as well as prescriptions for other antacids written during the 2-year period before the index date. We classified patients as having current exposure to a drug if they had received a prescription for the drug in the 45-day period before the index date and were otherwise not exposed. We defined the risk of antibiotic exposure for each agent separately and for antibiotics as a group. We evaluated the following classes of antibiotics: cephalosporins, macrolides, penicillins and tetracyclines. We examined clindamycin and trimethoprimsulfamethoxazole individually, and did the same for each of the following commonly used quinolone agents: levofloxacin, gatifloxacin, moxifloxacin and ciprofloxacin. We classified all other antibiotics as "other." Because we excluded patients with exposure to metronidazole and oral vancomycin therapy in the 90 days before the index date, we were unable to evaluate metronidazole as a possible risk factor. 


\section{Definition of covariates}

We used both databases to identify any comorbid gastrointestinal illnesses diagnosed in the 2 years before the index date, including inflammatory bowel disease, irritable bowel syndrome, peptic ulcer disease, gastroesophageal reflux disease, diverticular disease and gastrointestinal malignant disease. Other comorbid illnesses identified were chronic obstructive pulmonary disease, coronary artery disease, congestive heart failure, renal failure, diabetes mellitus, cerebrovascular accident and cancer (including solid tumours and hematologic malignant disease). We also determined the number of hospital admissions in the period from 90 days to 2 years before the index date.

\section{Statistical analysis}

We determined the number of cases fulfilling our inclusion criteria as a function of calendar time and time from the last hospital admission. We based all analyses on conditional logistic regression to estimate the odds ratio as an approximation of the rate ratio for the risk factors under study. We estimated the adjusted rate ratios of community-acquired $C$. difficile infection for current use of antibiotics, proton pump inhibitors and histamine $_{2}$-receptor antagonists, after adjustment for sex, comorbidity and hospital stays. Antibiotics were analyzed as a group and separately by drugs and classes. We also used time strata to evaluate the adjusted risk of $C$. difficile-associated diarrhea as a function of time from the last antibiotic prescription received. We considered $p$ values less than 0.005 to be significant.

\section{Results}

For the 8-year study period, we identified 5673 hospital admissions in the MED-ECHO database for which $C$. difficileassociated diarrhea was listed as the primary diagnosis. Of these, 836 cases met our definition of community-acquired $C$. difficile infection: no hospital stay in the 90 days before the index admission, no prescription for metronidazole or oral

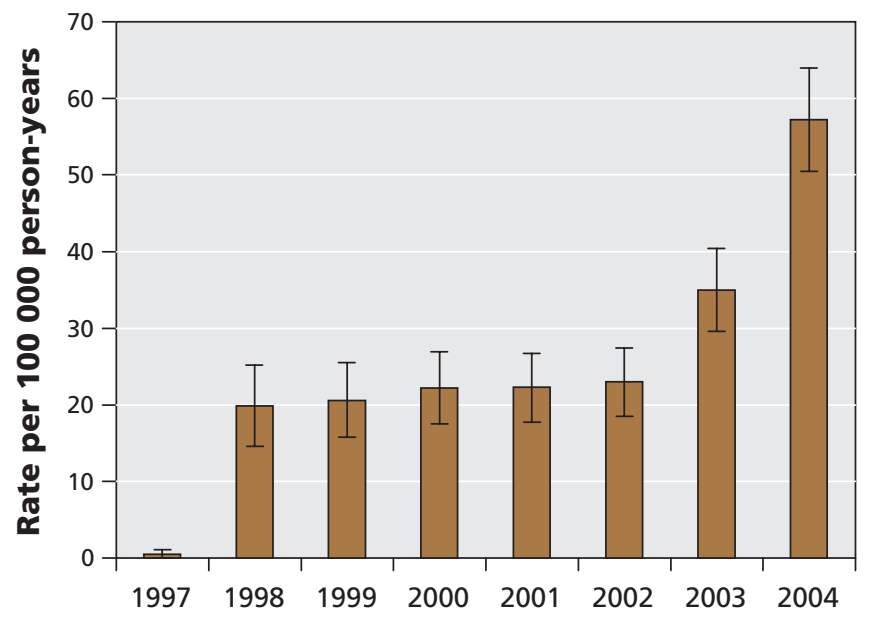

Figure 1: Population rates of community-acquired Clostridium difficile-associated diarrhea among people 65 years and older who required hospital admission in Quebec. Error bars $=95 \%$ confidence intervals. vancomycin in the 90 days before the index admission and no record of $C$. difficile infection as a secondary diagnosis during a previous hospital stay. The rate of community-acquired cases diagnosed per 100000 patient-years per calendar year was fairly stable between 1998 to 2002 and then rose significantly during 2003 and 2004 (Figure 1), similar to the pattern observed for patients in hospital. ${ }^{18}$ Most hospital admissions for incident $C$. difficile infection occurred within 90 days after a recent hospital stay (Figure 2), which confirms the importance of hospital admission as a risk factor for this disease.

People who met the case definition were older than controls, were more likely to be female and had had more encounters with physicians in the 2-year period before diagnosis (Table 1). Certain comorbidities, particularly the gastrointestinal disorders inflammatory bowel disease and irritable bowel syndrome, were more common among the cases. Renal failure was the only other comorbid illness that was significantly associated with $C$. difficile infection.

Only $394(47.1 \%)$ of the 836 cases and 639 (7.6\%) of the controls had been exposed to antibiotics in the 45-day period before the index admission. Using 90 days as an alternate definition of current exposure, 454 (54.3\%) of the cases and 1137 (13.6\%) of the controls had been exposed to any antibiotic before diagnosis. On multivariable analysis, all antibiotic classes other than tetracyclines, trimethoprim-sulfamethoxazole and antibiotics classified as "other" were associated with increased risk, but the highest risks were observed with clindamycin and cephalosporins and one of the quinolones (gatifloxacin). The adjusted rate ratios for each medication or class evaluated are shown in Figure 3.

To date, the at-risk period for $C$. difficile infection related to prior antibiotic exposure has not been well defined. On the basis of our results, the period of maximum risk related to antibi-

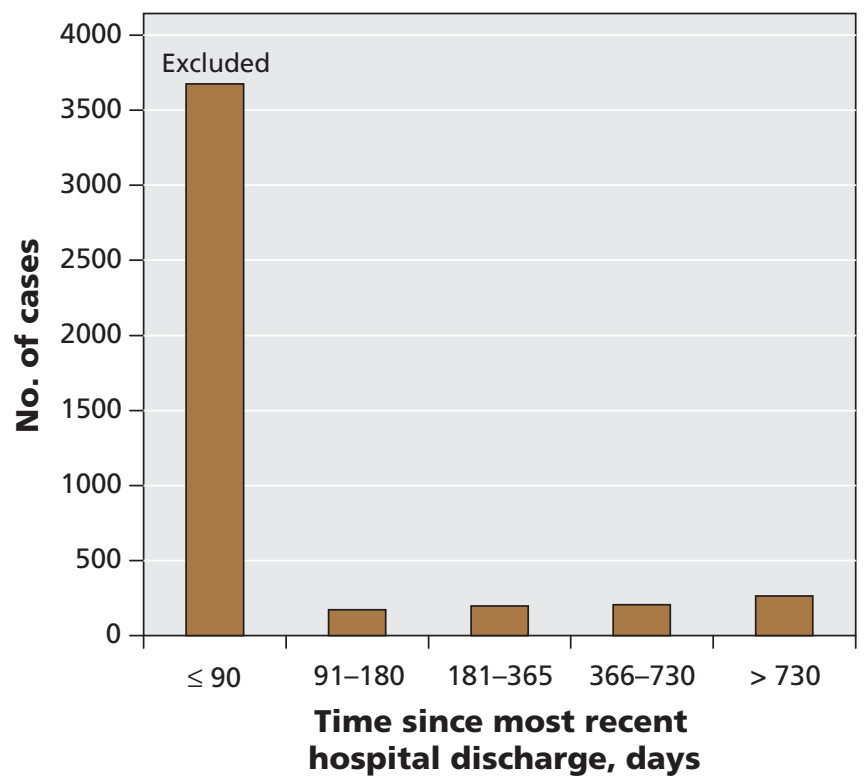

Figure 2: Distribution of community-acquired Clostridium difficile-associated diarrhea as a function of time from hospital admission in the 2 years before the index admission. 
otic exposure appears to be within 30 days after the start of antibiotic use, with a significant decrease after 45 days (Figure 4).

We also performed a sensitivity analysis in which community-acquired $C$. difficile was defined as greater than 180 days between the current and previous hospital admission. In that analysis, 665 of the 836 cases met the definition, and only $326(49 \%)$ of these 665 cases were exposed to antibiotics in the 45 days beforehand.

\section{Interpretation}

In this population-based study, we determined the period of risk of $C$. difficile infection that might be related to antibiotic exposure and found that about $50 \%$ of patients had no history of antibiotic exposure in the 45 days before admission because of $C$. difficile infection. We also demonstrated that a significant proportion of hospital admissions because of incident $C$. difficile infection occurred within 90 days after discharge from hospital, confirming the importance of the hospital experience in the epidemiology of this disease.

Using a large sample of patients identified from the community, we have again documented that antibiotic use is not a prerequisite to the development of $C$. difficile infection. ${ }^{4,5}$ A number of smaller studies have reported similar observations., ${ }^{3,19-22}$ Substantially lower rates of prior antibiotic exposure in communityacquired $C$. difficile infection support the tenet that there may be significant confounding of the association between antibiotics and $C$. difficile infection with hospital admission.

Clindamycin, cephalosporins and gatifloxacin were the antibiotics associated with the highest risk in this study. Recent studies of nosocomial $C$. difficile infection in the same province $^{23,24}$ demonstrated no significant increase in risk asso-

Table 1: Characteristics of 836 elderly patients with community-acquired Clostridium difficile infection and 8360 controls

\begin{tabular}{|c|c|c|c|c|}
\hline \multirow[b]{2}{*}{ Characteristic } & \multicolumn{2}{|c|}{ No. $(\%)$ of patients* } & \multicolumn{2}{|c|}{ Rate ratio } \\
\hline & $\begin{array}{c}\text { Cases } \\
n=836\end{array}$ & $\begin{array}{l}\text { Controls } \\
n=8360\end{array}$ & Unadjusted & $\begin{array}{l}\text { Adjusted } \neq \\
(95 \% \mathrm{Cl})\end{array}$ \\
\hline \multicolumn{5}{|l|}{ Demographic characteristics } \\
\hline Age, mean (SD) & $79.8 \quad(6.8)$ & $77.5(6.3)$ & & $1.4 \S(1.3-1.5) \emptyset$ \\
\hline Follow-up, yr, mean (SD) & $3.8 \quad(2.2)$ & $3.8(2.2)$ & & \\
\hline Sex, female & $554(66.3)$ & $4944(59.1)$ & 1.4 & $1.3(1.0-1.4)$ \\
\hline \multicolumn{5}{|l|}{ Use of health care system } \\
\hline No. of physician visits in previous 2 yr, mean (SD) & $12.8(25.0)$ & $9.2(18.8)$ & & \multirow[b]{2}{*}{$2.2(2.0-2.4)$ ा } \\
\hline $\begin{array}{l}\text { No. of hospital admissions in previous } 2 \mathrm{yr} \text {, } \\
\text { mean (SD) }\end{array}$ & $1.4 \quad(1.5)$ & $1.3(1.4)$ & & \\
\hline No. of days in hospital in previous $2 \mathrm{yr}$, mean (SD) & $18.5(33.8)$ & $11.0(23.5)$ & & \\
\hline \multicolumn{5}{|l|}{ Concurrent medical conditions } \\
\hline Inflammatory bowel disease & 41 (4.9) & $88(1.1)$ & 4.7 & $4.1(2.6-6.6) \uparrow$ \\
\hline Irritable bowel syndrome & $86(10.3)$ & 117 (1.4) & 5.5 & $3.4(2.3-5.0) \uparrow$ \\
\hline Peptic ulcer disease & $35 \quad(4.2)$ & $269 \quad(3.2)$ & 1.3 & $1.1 \quad(0.7-1.7)$ \\
\hline Gastroesophageal reflux disease & $74 \quad(8.9)$ & $536 \quad(6.4)$ & 1.4 & $1.0(0.7-1.4)$ \\
\hline Diverticular disease & $96(11.5)$ & $636(7.6)$ & 1.6 & $1.2(0.9-1.5)$ \\
\hline Chronic obstructive pulmonary disease & $325(38.9)$ & $2381(28.5)$ & 1.6 & $1.1(0.9-1.3)$ \\
\hline Coronary artery disease & $217(21.0)$ & $1333(15.9)$ & 1.4 & $1.3(0.9-1.4)$ \\
\hline Congestive heart failure & $175(20.9)$ & $668(8.0)$ & 1.4 & $0.9 \quad(0.7-1.2)$ \\
\hline Renal failure & $50 \quad(6.0)$ & $128 \quad(1.5)$ & 1.8 & $1.7(1.3-2.2) \pi$ \\
\hline Diabetes mellitus & $171(20.4)$ & $1146(13.7)$ & 1.2 & $1.2(1.0-1.5)$ \\
\hline Cerebrovascular accident & $163(19.5)$ & $745 \quad(8.9)$ & 1.4 & $1.2(1.0-1.5)$ \\
\hline Colon cancer & $25 \quad(3.0)$ & $126 \quad(1.5)$ & 1.3 & $1.2(0.7-1.9)$ \\
\hline Other gastrointestinal malignant disease & $18 \quad(2.2)$ & 114 (1.4) & 1.4 & $1.2(0.8-1.8)$ \\
\hline Hematologic malignant disease & $27 \quad(3.2)$ & $80(1.0)$ & 1.7 & $1.5(0.9-2.4)$ \\
\hline Other malignant disease & $223(26.7)$ & $1768(21.1)$ & 1.0 & $1.0 \quad(0.8-1.2)$ \\
\hline \multicolumn{5}{|c|}{$\begin{array}{l}\text { Note: SD = standard deviation. } \\
\text { *Unless indicated otherwise. } \\
\text { tRate ratios greater than } 1 \text { imply that the rate of hospital admission because of Clostridium difficile-associated diarrhea was greater among patients with the } \\
\text { particular exposure than among those without. } \\
\text { fAdjusted for all variables in this table (except number of physician visits and number of days in hospital) and exposure to antibiotics, proton pump inhibitors and } \\
\text { histamine } e_{2} \text {-receptor antagonists. } \\
\text { \$Per } 5 \text { years. } \\
\uparrow p<0.005 .\end{array}$} \\
\hline
\end{tabular}


ciated with clindamycin. Clindamycin and cephalosporins are frequently associated with gastrointestinal side effects and have previously been labelled high-risk drugs associated with $C$. difficile-associated diarrhea. ${ }^{2}$ These features are likely to increase ascertainment bias, since patients with gastrointestinal symptoms, particularly those who have received reputedly high-risk antibiotics, are more likely to be tested. The antibiotic associated with the highest risk for $C$. difficileassociated diarrhea has not been consistent among studies, and almost all antibiotics have been associated with an increased risk of $C$. difficile infection, irrespective of their spectrum of activity on either the normal flora or $C$. difficile. The inconsistency among studies of results implicating particular antibiotics, as well as the nonspecificity of the drugs, support the hypothesis that some of the risk attributed to antibiotics may be confounded.

The strengths of our study include use of a communitybased population of high-risk patients for whom there was complete data about medication exposure and hospital admission. We also used a clinically relevant case definition. By restricting the population to community-based patients, we controlled for factors associated with hospital admission. We controlled for confounding by severity of illness both by matching and by adjustment in the analysis. We studied a highrisk population and included incident cases only. Antibiotic exposure among patients who have had a previous episode of $C$. difficile infection may be modified by the first event, and physi- cians may be less likely to use antibiotics considered to present a high risk. Therefore, the exclusion of cases with recurrent disease decreased the risk of bias in the antibiotic estimates.

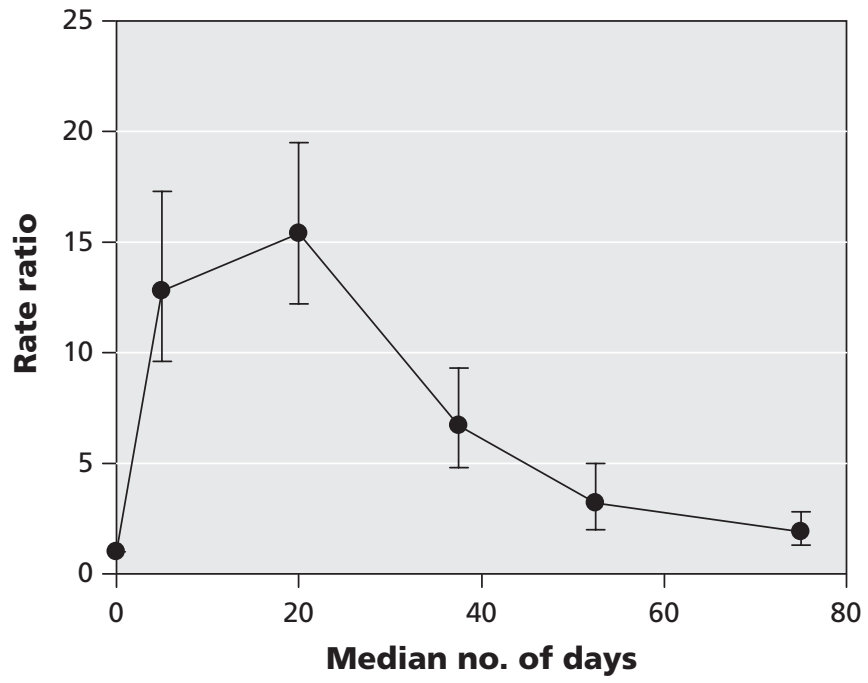

Figure 4: Risk of hospital admission because of Clostridium dif ficile infection as a function of time from most recent antibiotic prescription. Values shown are rate ratios for patients with C. difficile infection $(n=836)$ relative to those without $C$. difficile infection $(n=8360)$.

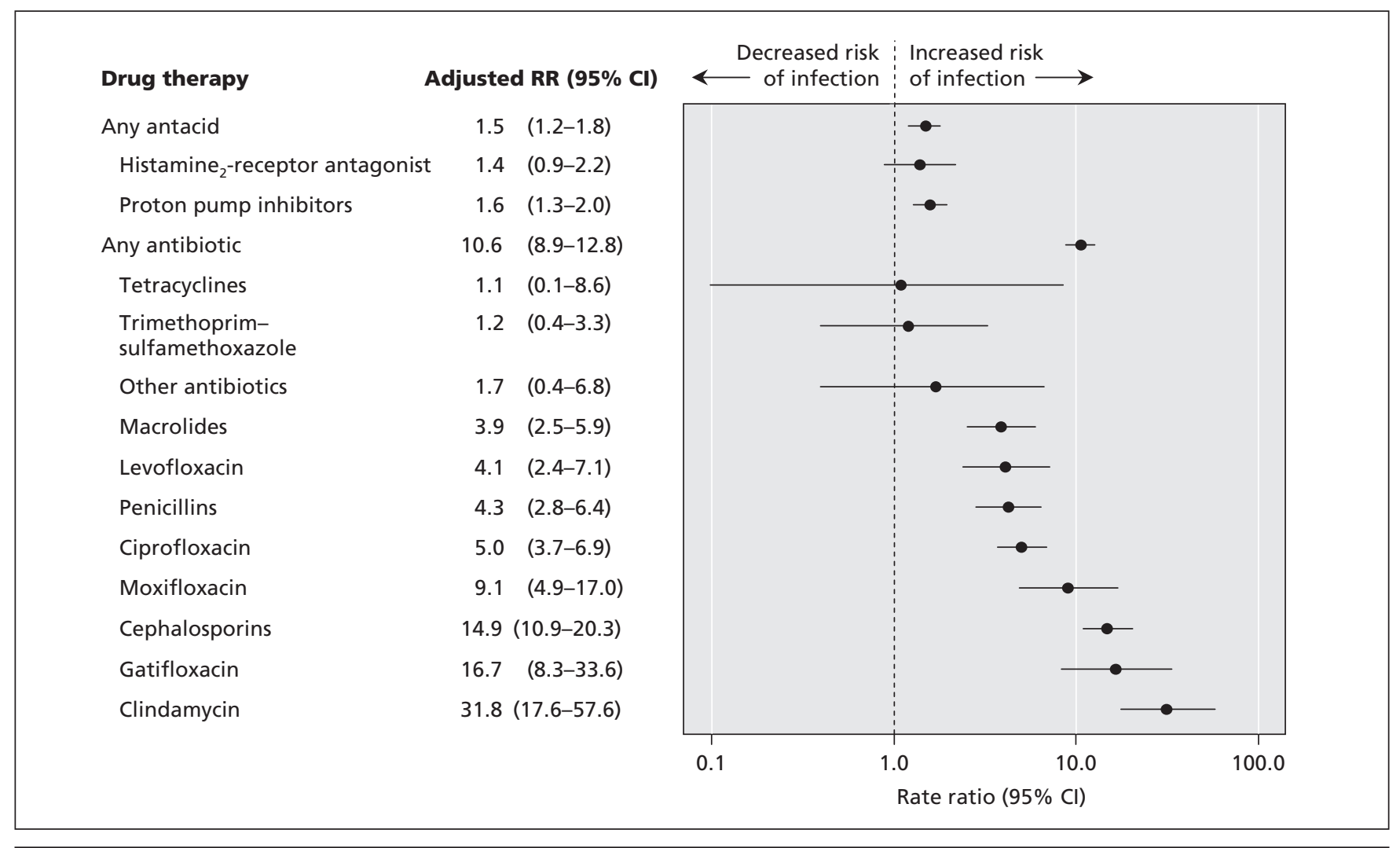

Figure 3: Adjusted rate ratios (RRs) of Clostridium difficile infection among patients exposed to antibiotics and gastric suppressive therapy in the 45 days before the index date compared with patients not exposed in that period. Adjustments were made for the variables in Table 1 and for the agents listed in the above figure. $\mathrm{Cl}=95 \%$ confidence interval. 
Our study has limitations. The study population was restricted to a specific population of elderly patients with at least 1 prior hospital admission in the previous 8 years. Because the case definition was restricted to patients with severe infection, the risk factors observed may differ from those for the general population and for patients with less severe disease.

The information obtained from administrative databases also has limitations. Two previous studies ${ }^{25,26}$ examining a diagnosis of $C$. difficile infection based on codes from the International Classification of Diseases, 9th revision, showed that the definition had high specificity (over 99\%) but lower sensitivity, which could result in case misclassification and might have affected some of the risk estimates that we obtained. We did not obtain any confirmatory laboratory data, as this information was not available in the database; however, it is unlikely that patients who had been admitted to hospital would be recorded as having C. difficile infection in the absence of testing. The drug database might not have taken into consideration administration of antibiotics or other drugs from physician samples, but this was deemed unlikely to be significant. It is also possible that patients who were classified as having been exposed to antibiotics because a prescription was dispensed did not actually take the medication. Some of the patients defined as having community-acquired infection may have been residing in long-term care institutions, but such cases probably represented less than 5\% of the elderly population $^{27}$ and were unlikely to substantially affect the estimates.

Similarly, the assignment of comorbid diagnoses using administrative databases has limitations, and previous research with such databases has shown that many of the diagnoses of comorbidity have high specificity, with sensitivity varying greatly by condition. ${ }^{16,28}$ This might have led to misclassification in our study, and since these misclassifications were likely nondifferential, our estimates of relative risk were likely underestimated. We believe, however, that the extent of such information bias was minimal. Therefore, the associations that we found were likely real, especially given that they have been documented in previous research, including studies that we conducted using another validated research database. ${ }^{4,5}$

Community-acquired $C$. difficile infections were common and developed without prior exposure to antibiotics in the study population. Testing for $C$. difficile should be considered in community patients with diarrhea in whom a history of antibiotic exposure cannot be elicited.

\section{This article has been peer reviewed.}

Competing interests: Sandra Dial received an honorarium from GlaxoSmithKline for a review article on proton pump inhibitors and the risk of enteric infections. Andre Dascal has received speaker fees from Altana Pharma and AstraZeneca, and research support from Merck Frosst Canada. Samy Suissa is a member of the advisory boards of Pfizer Canada, Boehringer Ingelheim and GlaxoSmith Kline, has received consultancy fees from Merck, Bayer and Sanofi-Aventis and has received research grants from Organon and Wyeth. Alan Barkun has received consultancy and speaker fees from AstraZeneca and Abbott. No competing interests declared by Abbas Kezouh.

Contributors: Sandra Dial and Samy Suissa conceived and designed the study, Sandra Dial and Abbas Kezouh acquired the data, and Abbas Kezouh, Samy Suissa and Sandra Dial analyzed and interpreted that data. Andre Dascal and Alan Barkun contributed substantially to the conception and design of the study and the analysis and interpretation of the data. All of the authors participated in drafting or revising the manuscript and approved the final version to be published.

\section{REFERENCES}

1. Bartlett JG. Narrative review: the new epidemic of Clostridium difficile-associated enteric disease. Ann Intern Med 2006;145:758-64.

2. Kelly CP, Pothoulakis C, Lamont JT. Clostridium difficile colitis. N Engl J Med 1994;330:257-62.

3. Wilcox MH, Mooney L, Bendall R, et al A case-control study of communityassociated Clostridium difficile infection. J Antimicrob Chemother 2008;62:38896. Epub 2008 Apr 22.

4. Dial S, Delaney JA, Schneider V, et al. Proton pump inhibitor use and risk of community-acquired Clostridium difficile-associated disease defined by prescription for oral vancomycin therapy. CMAJ 2006;175:745-8.

5. Dial S, Delaney JA, Barkun AN, et al. Use of gastric acid-suppressive agents and the risk of community-acquired Clostridium difficile-associated disease. JAMA 2005;294:2989-95.

6. Blossom DB, McDonald LC. The challenges posed by reemerging Clostridium difficile infection. Clin Infect Dis 2007;45:222-7.

7. Bartlett JG. Historical perspectives on studies of Clostridium difficile and C. difficile infection. Clin Infect Dis 2008;46(Suppl 1):S4-11.

8. Dial S, Delaney JA, Barkun AN, et al. Gastric acid-suppressive agents and risk of Clostridium difficile-associated disease — author response [letter]. JAMA 2006;295: 2600-1.

9. Bartlett JG. Antibiotic-associated diarrhea. Clin Infect Dis 1992;15:573-81.

10. Guerrant RL, Van Gilder T, Steiner TS, et al. Practice guidelines for the management of infectious diarrhea. Clin Infect Dis 2001;32:331-51.

11. Svenungsson B, Lagergren A, Lundberg A. Clostridium difficile cytotoxin B in adults with diarrhea: a comparison of patients treated or not treated with antibiotics prior to infection. Clin Microbiol Infect 2001;7:447-50.

12. Climo MW, Israel DS, Wong ES, et al. Hospital-wide restriction of clindamycin: effect on the incidence of Clostridium difficile-associated diarrhea and cost. Ann Intern Med 1998;128:989-95.

13. Pierce PF Jr, Wilson R, Silva J Jr, et al. Antibiotic-associated pseudomembranous colitis: an epidemiologic investigation of a cluster of cases. J Infect Dis 1982;145:269-74.

14. Bartlett JG. Antimicrobial agents implicated in Clostridium difficile toxin-associated diarrhea of colitis. Johns Hopkins Med J 1981;149:6-9.

15. Lowe DO, Mamdani MM, Kopp A, et al. Proton pump inhibitors and hospitalization for Clostridium difficile-associated disease: a population-based study. Clin Infect Dis 2006;43:1272-6.

16. Rahme E, Pettitt D, Lelorier J. Determinants and sequelae associated with utilization of acetaminophen versus traditional nonsteroidal antiinflammatory drugs in an elderly population. Arthritis Rheum 2002;46:3046-54.

17. Tamblyn R, Lavoie G, Petrella L, et al. The use of prescription claims databases in pharmacoepidemiological research: the accuracy and comprehensiveness of the prescription claims database in Quebec. J Clin Epidemiol 1995;48:999-1009.

18. Hebert B. Current epidemiology of CDAD in Quebec [presentation]. Proceedings of the International Conference on Clostridium difficile; 2005 Oct 14. Montréal (QC): Institut national de santé publique du Québec; 2005. Available: www.inspq.qc.ca/aspx /docs/InfectionsNosocomiales/CDifficile/20051014_Cdifficile_Hubert1.pdf (accessed 2008 Jul 11).

19. Hirschhorn LR, Trnka Y, Onderdonk A, et al. Epidemiology of communityacquired Clostridium difficile-associated diarrhea. J Infect Dis 1994;169:127-33.

20. McFarland LV, Clarridge JE, Beneda HW, et al. Fluoroquinolone use and risk factors for Clostridium difficile-associated disease within a Veterans Administration health care system. Clin Infect Dis 2007;45:1141-51.

21. Kutty PK, Benoit SR, Woods CW, et al. Emerging Clostridium difficile-associated disease in the community and the role of non-antimicrobial risk factors [abstract LB-28]. 45th annual meeting of the Infectious Diseases Society of America; 2007 Oct 4-7; San Diego. p. 242. Available: www.idsociety.org/WorkArea/showcontent .aspx?id=2080 (accessed 2008 Aug 25)

22. Severe Clostridium difficile-associated disease in populations previously at low risk - four states, 2005. MMWR Morb Mortal Wkly Rep 2005;54:1201-5.

23. Pepin J, Saheb N, Coulombe MA, et al. Emergence of fluoroquinolones as the predominant risk factor for Clostridium difficile-associated diarrhea: a cohort study during an epidemic in Quebec. Clin Infect Dis 2005;41:1254-60.

24. Loo VG, Poirier L, Miller MA, et al. A predominantly clonal multi-institutional outbreak of Clostridium difficile-associated diarrhea with high morbidity and mortality. N Engl J Med 2005;353:2442-9.

25. Dubberke ER, Reske KA, McDonald LC, et al. ICD-9 codes and surveillance for Clostridium difficile-associated disease. Emerg Infect Dis 2006;12:1576-9.

26. Scheurer DB, Hicks LS, Cook EF, et al. Accuracy of ICD-9 coding for Clostridium difficile infections: a retrospective cohort. Epidemiol Infect 2007;135:1010-3. Epub 2006 Dec 7.

27. Vies des générations et personnes âgeés: aujourd'hui et demain. Québec (QC) : Institut de la statistique du Québec; 2007. Available: www.bdso.gouv.qc.ca/docs-ken /multimedia/PB01614FR_VieGenerationVo2_2007.pdf (accessed 2008 July 11).

28. Wilchesky M, Tamblyn RM, Huang A. Validation of diagnostic codes within medical services claims. J Clin Epidemiol 2004;57:131-41.

Correspondence to: Dr. Sandra Dial, Department of Medicine,

Montreal Chest Institute and Sir Mortimer B. Davis-Jewish General

Hospital, McGill University, 3650 rue St-Urbain, Rm. K1.14,

Montréal QC H2X 2P4; fax 514 843-2083; sandra.dial@mcgill.ca 